Research Journal of Biological Sciences 7 (6): 234-237, 2012

ISSN: $1815-8846$

(C) Medwell Journals, 2012

\title{
Study of Anxiety and Style Control Parenting
}

\author{
${ }^{1}$ Fereshteh Ghaljaei, ${ }^{2}$ Behzad Narouie, ${ }^{1}$ Mahin Naderifar, \\ ${ }^{3}$ Mohammad Ghasemi-Rad and ${ }^{4}$ Hamideh Hanafi-Bojd \\ ${ }^{1}$ Faculty of Nursing and Midwifery, Zahedan University of Medical Sciences, Zahedan, Iran \\ ${ }^{2}$ Clinical Research Development Center, Ali-Ebne-Abitaleb Hospital, \\ Zahedan University of Medical Sciences, Zahedan, Iran \\ ${ }^{3}$ Genius and Talented Student Organization, Urmia University of Medical Sciences, Urmia, Iran \\ ${ }^{4}$ Clinical Research Development Center, Zahedan University of Medical Sciences, Zahedan, Iran
}

\begin{abstract}
Strong, desirable and mutual relationship between parents and child is necessary so that nurses can achieve their duties and delivery of care to the child. This relationship should be identified in context of family (Style control parenting) in order for the nurses to maintain those parts of family relationship related to nursing duties. Anyhow, the actions should be planned in a manner that be well-adjusted with children' morale and help to decrease child's anxiety. The present descriptive correlation study aims to determine the relationship of behavioral models of parent with their children's anxiety (370 students in age 13-15) in 10 governmental girl guidance schools, Dist. 6 of Tehran city. The tools were questionnaires planned for students and parents consisting demographic characteristics, physiologic symptoms of anxiety, Spiel Berger Anxiety Test for parents and Reynolds and Richmond Anxiety Tests for students. The amount of anxiety among these groups was analyzed using Chi-square Test and Fisher Exact Test in SPSS statistical software. Results showed that the amount of anxiety among students was $33 \%$ with the most anxiety (92\%) among adolescents who evaluated their parents' behavior as autocratic $(\mathrm{p}=0.001)$ and the least anxiety $(7.6 \%)$ in adolescents who had democratic parents $(p=0.003)$. These findings shows that there is statistically significant relationship between anxiety and style control parenting $(\mathrm{p}<0.05),(\mathrm{df}=2)$. Style control parenting plays an important role in children's anxiety, therefore health care providers can be effective in decreasing children' anxiety by teaching style control parenting.
\end{abstract}

Key words: Style control parenting, anxiety, girls, students, Iran

\section{INTRODUCTION}

Anxiety is considered as an inseparable part of human experience and nature, a mode which is created by stress. During the history, people have encountered many social, economical and technological changes resulted in reactions against stress situations (Antai-Otong, 1995). Anxiety is a vague annoyance feeling together with apprehension which has been developed in response to internal and external stimulations and can lead to cognitive, affective, physical and behavioral symptoms (Boyd, 2002). Anxiety disorders is one of the most common psychological disorders, as annually 23 millions persons in USA are affected and one of four involves in anxiety (Carson, 2000). Women experience anxiety disorders twice more than men (Dikestin, 2000).

Regarding etiology of anxiety, different causes has been addressed from psychological, biological, ethological, genetic and social-cultural theory points of view (Varcralis, 2000). Whereas parents deal with their children in different styles, the type of behavior with child can be influenced by cultural issues, their social class and economical sources (Wongs and Wally, 2003). According to developmental theories of anxiety, acceptance of children by their parents, control style and their behaviors are related with appearing symptoms of anxiety in children (McLeod et al., 2003). Although, there are many behaviors in style control parenting but three autocratic, non-interventional and democratic models are mostly used (Whaley and Wongs, 2001).

Results of studies show an increase in various types of mental disorders such as anxiety and also demonstrate the effects of style control parenting in developing such disorders. The results of some studies about style control parenting show that the other methods should be found to control and decrease anxiety in children. Strong,

Corresponding Author: Behzad Narouie, Clinical Research Development Center, Ali-Ebne-Abitaleb Hospital, Zahedan University of Medical Sciences, Zahedan, Iran 
desirable and mutual relationship between parents and child is necessary so that nurses can achieve their duties and delivery of care to the child. This relationship should be identified in context of family (Style control parenting) in order for the nurses to maintain those parts of family relationship related to nursing duties.

On the other hand, nurses of school can play an important role in decreasing anxiety arising from style control parenting and preventing mental and psychological diseases by acquaintance with morale of children and adolescents and informing parents of developmental needs of their children. Considering this issue, significance of the best kind of behavior of parents with student is distinguished. This study aims to determine relationship between students' anxiety with style control parenting.

\section{MATERIALS AND METHODS}

This research is a descriptive correlation study performed to determine the relationship between students' anxiety with style control parenting in 2005 (1384). The sample consisted of 370 students in 3rd grade of governmental guidance school in Dist. 6 of Tehran city by using 2 -stage sampling method. At first, names of all schools in Dis. 6 of Tehran were prepared and ten schools were randomly selected then two classes from each school were randomly selected. Students were under guardianship of their main parents and did not have any history of known physical or mental diseases. As anxiety in students could be the result of morbid anxiety of their parents, parents of the sample students should have no physical and mental diseases and morbid anxiety so that the researchers can reach to anxiety resulting from style control parenting, therefore parents were screened by EspillBerger Test and were omitted from research in case of any problem. After taking the permission from the school principle, researchers chose times which student had either no class or exercise classes. The aim was to have all students in equal condition and without stress. The vital sign were calculated from all participants equally in sitting position. Those with abnormal signs were referred to health care centers for further evaluation. The questionnaires were given to student to fill and one for parents was taken home.

Tools for gathering data in this research consisted of two separate questionnaires relating to parents and students. The first questionnaire included demographic characteristics of parents (9 questions), Diana Brinder Test for recognition of style control parenting (which consists of 20 questions related to control parenting and each question had 3 different answers. One was chosen and according to answer we could determine type of parenting) and eschpillberger evident and covert anxiety test (40 questions) based on Likert scale. Achievement of score (20-42) means light anxiety, (43-64) means middle anxiety and (65-80) means intense anxiety. The second questionnaire consisted of demographic characteristics of students (4 questions), records of physiologic symptoms of students' anxiety (9 questions) (In this research, physiologic symptoms means records of blood pressure, pulse, respiration, temperature, symptoms of abdominal pain, nausea, diarrhea, urine iteration, paleness, fever) and Revised Reynolds Richmond Test of anxiety (37 questions) in which achieving score of $(0-19)$ is non-anxiety status and (20-27) shows anxiety.

To determine validity and reliability of the style control parenting test, content validity method was used and reliability of which was reached from re-test method in the amount of 0.75. Assessment tools of parent and students' anxiety was standard and enjoyed high level of validity and reliability. Also, to ensure validity of physiologic symptoms, a fixed and same control tools were used and across reliability method was used to ensure reliability of the form for recording vital signs. Analysis of data was performed by using Fisher Exact Test and Chi-square Test in SPSS statistical software.

\section{RESULTS}

In present study, most students $(63.2 \%)$ were in 14 years age group and $57.3 \%$ had self-employed fathers, $60.5 \%$ had a desirable economical status and $76.8 \%$ were not in menstruation period at the time of research, regarding anxiety of students, results showed that $33 \%$ of students under study suffered from anxiety and $67 \%$ of them had no anxiety. There was no statistical significant relationship between anxiety and variables of age, birth rank, menstruation, father's age and parent's level of $(p>0.05)$ but there was a statistically significant relationship between anxiety and its physiologic symptoms $(\mathrm{p}=0.007)$, parents' occupation (both mother and father $)(p=0.017)$ and economical status of parents $(\mathrm{p}=0.016)$.

Findings of this research about father control style showed that $9.2 \%$ of them had non-interventional control style, $23.5 \%$ had autocratic control style and $67.3 \%$ of them had democratic control style (Table 1). Regarding

Table 1: Absolute and relative frequency distribution of control style of

\begin{tabular}{|c|c|c|c|c|}
\hline \multirow{2}{*}{$\begin{array}{l}\text { Style } \\
\text { control } \\
\text { parenting }\end{array}$} & \multicolumn{2}{|c|}{ Father } & \multicolumn{2}{|c|}{ Mother } \\
\hline & No. & Percentage & No. & Percentage \\
\hline Non-intervention & 34 & 9.2 & 16 & 4.3 \\
\hline Despotic & 87 & 23.5 & 72 & 19.5 \\
\hline Democratic & 249 & 76.3 & 282 & 76.2 \\
\hline Total & 370 & 100.0 & 370 & 100.0 \\
\hline
\end{tabular}


Res. J. Biol. Sci., 7 (6): 234-237, 2012

\begin{tabular}{|c|c|c|c|c|c|c|c|c|c|}
\hline \multirow{2}{*}{$\begin{array}{l}\text { Mother control } \\
\text { style frequency } \\
\text { Students' anxiety }\end{array}$} & \multicolumn{2}{|c|}{ Non-intervention } & \multicolumn{2}{|c|}{ Despotic } & \multicolumn{2}{|c|}{ Democratic } & \multicolumn{2}{|c|}{ Total } & \multirow[b]{2}{*}{ Test result } \\
\hline & No. & Percentage & No. & Percentage & No. & Percentage & No. & Percentage & \\
\hline Not exist & 1 & 6.2 & 11 & 15.3 & 236 & 83.7 & 284 & 67 & $\chi^{2}=149.40, \mathrm{df}=2$ \\
\hline Exist & 15 & 93.8 & 61 & 84.7 & 46 & 16.3 & 122 & 33 & $\tilde{\mathrm{p}}<0.001$, meaningful \\
\hline Total & 16 & 100.0 & 72 & 100.0 & 282 & 100.0 & 370 & 100 & \\
\hline
\end{tabular}

Table 3: Absolute and relative frequency distribution and anxiety status of girl students of guidance school based on control style of fathers, 1384 (2005)

\begin{tabular}{|c|c|c|c|c|c|c|c|c|c|}
\hline \multirow{2}{*}{$\begin{array}{l}\text { Father control } \\
\text { style frequency } \\
\text { Students' anxiety }\end{array}$} & \multicolumn{2}{|c|}{ Non-Intervention } & \multicolumn{2}{|c|}{ Despotic } & \multicolumn{2}{|c|}{ Democratic } & \multicolumn{2}{|c|}{ Total } & \multirow[b]{2}{*}{ Test result } \\
\hline & No. & Percentage & No. & Percentage & No. & Percentage & No. & Percentage & \\
\hline Not exist & 11 & 32.4 & 7 & 8 & 230 & 92.4 & 248 & 67 & $\chi^{2}=149.40, \mathrm{df}=2$ \\
\hline Exist & 23 & 67.6 & 80 & 92 & 19 & 7.6 & 122 & 33 & $\mathrm{p}<0.001$, meaningfu \\
\hline Total & 34 & 100.0 & 87 & 100 & 349 & 100.0 & 370 & 100 & \\
\hline
\end{tabular}

type of mothers' control style showed that $4.3 \%$ had non interventional control style, $19.5 \%$ had autocratic control style and $76.2 \%$ had democratic control style (Table 1 ), it means democratic control style is dominant in both groups (Table 2).

Findings about student's anxiety status based on style control parenting shows that $93.8 \%$ of mothers with non-interventional control style, $84.7 \%$ of mothers with autocratic control style and $16.3 \%$ of mothers with democratic control styles anxious children, it means that in democratic control style of mothers, students had the least anxiety (Table 3).

Chi-square Test showed that there is a significant relationship between students' anxiety status and style control parenting $(\mathrm{p}<0.001),(\mathrm{df}=2)$. Also, findings about relationship of students' anxiety status with fathers' control style shows that $92 \%$ of fathers with autocratic control style, $67.6 \%$ of fathers with non-interventional control style and $7.6 \%$ of fathers with democratic control style had anxious children, meaning that the least anxiety of students is related to fathers with democratic control style (Table 3). Chi-square Test also showed that there is a significant relationship between students' anxiety status and fathers' control style $(\mathrm{p}<0.001)(\mathrm{df}=2)$ (Table 3$)$.

\section{DISCUSSION}

Findings shows that the most style control parenting of mothers under study (76.2\%) and the most style control parenting of fathers under study $(67.3 \%)$ has been of democratic type which is consistent with the results of Izadpoor (1380) research showing that mothers and fathers in society prefer democratic education method and pattern to the other two methods. Also, findings showed that there was a significant relationship between style control parenting of mothers and students' anxiety status confirming the results of Hudson and Rapee (2003)'s research. In the methods that mothers have more intervention in duties of children and encourage them less, anxiety in their children is high. Considering significance of relationship between students' anxiety status and style control parenting of fathers, results of Jerm et al. (2002)'s research show that fathers have more involvements with their girls and amount of their involvement is effective in anxiety of their children.

According to the results, the researchers claim that style control parenting is related to the amount of anxiety of children' anxiety and is effective in its creation. Nurses in schools, considering significance of health of young society and its risks and consequences of anxiety can play an important role in on time preventing and decreasing anxiety resulting from style control parenting. Considering results of this research, it is suggested that the following topics in frame of future researches are emphasized.

According to the results which show that there is relationship between different control parenting and anxiety in students, there is usefulness of data in nursing fields. Nurses are health group which have close relation with families and their education could have great impact on family style. This shows that every school should have nurse present and all college nursing student should be aware and educated in this regard. This itself brings the inclusion of family mental health education as one of the subjects which should be taught in schools. The parents should also be able to contact the school nurse regarding the problems they are facing in their children education.

\section{CONCLUSION}

Relation between parents' anxiety is assessed with anxiety of children. Also, style control parenting can be studied from viewpoint of anxious students; in addition, considering results of this research can not be generalized throughout of the country, it is suggested that the next researches to be performed with different cultures in different provinces. 


\section{ACKNOWLEDGEMENTS}

The respectable officials of Ministry of Education and Administrators of Schools who facilitate performance of this research in school, also parents and students participated in this research and respectable officials of Faculty of Nursing and Midwifery are hereby appreciated and researchers would like to acknowledge the Clinical Research Development Center of Ali-Ebne-Abitaleb Hospital, Zahedan University of Medical Sciences for its help in preparing this study.

\section{REFERENCES}

Antai-Otong, D., 1995. Psychiatric Nursing: Biological and Behavioral Concepts. Saunders Co., Philadelphia, pp: 192-196.

Boyd, M.A., 2002. Psychiatric Nursing: Contemporary Practice. 2nd Edn., Lippincott Williams and Wilkins, Philadelphia, ISBN-13: 9780781748568 , pp: 454-458.

Carson, V.B., 2000. Mental Health Nursing: The NursePatient Journey. 2nd Edn., W.B. Saunders, Philadelphia, Pages: 1182.

Dikestin, T., 2000. Gender differences in mood and anxiety disorders: From bench to bedside: American psychiatric press review of psychiatry. Am. J. Psychiat., 157: 1186-1187.
Hudson, J.L. and P.M. Rapee, 2003. Parent-child interaction and anxiety disorders: Anobservational study. Behav. Res. Ther., 39: 1411-1427.

Izadpoor, A., 1380. Study of methods of child education of fathers and mothers whose children use nursery. M.S. Thesis, Welfare and Rehabilitation University.

Jerm, A.F., K.B.G. Dear, B. Rodgers and H. Christensen, 2002. Interaction between mothers and fathers affection as a risk factor for anxiety and depression symptoms socpsychiatry psychiatry epidemiology. Soc. Psychiatry Psychiatr Epidemiol., 38: 173-179.

McLeod, B.D., M. Sigman, W.C. Hwang and B.C. Chu, 2003. Parenting and Childhood anxiety: Theory, empirical finding and future direction. J. Child Psychol. Psychiatry, 44: 134-151.

Varcralis, E.M., 2000. Psychiatric Nursing Clinical Guide: Assessment Tools and Diagnosis. Saunders, Ottawa, Canada, ISBN-13: 9780721683362 , pp: 237-293.

Whaley, L.F. and D.L. Wongs, 2001. Nursing care of infantry and children. Mosby, Philadelphia, pp: $880-901$.

Wongs, D.L. and L.F. Wally, 2003. Nursing Care of Infants and Children. Mosby, Missouri. 